\title{
To what extent do supervised drug consumption services incorporate non-injection routes of administration? A systematic scoping review documenting existing facilities
}

Kelsey A. Speed ${ }^{1,2}$, Nicole D. Gehring ${ }^{1,2}$, Katherine Launier $^{2}$, Daniel O'Brien ${ }^{1,2}$, Sandy Campbell ${ }^{3}$ and Elaine Hyshka ${ }^{1,2^{*}}$ (D)

\begin{abstract}
Background: Most of the existing research on supervised consumption services (SCS) is focused on injection drug use. Less is known about the applicability of SCS for people who consume drugs orally, intranasally, or through inhalation. This is problematic because people who use drugs through modes other than injection are also at risk of overdose death and other harm, and experience barriers accessing health and social services. We aimed to describe existing SCS models that accommodate these alternate routes of drug consumption, and synthesize available information on characteristics of program participants.
\end{abstract}

Methods: We conducted a systematic scoping review of 9 peer-reviewed and 13 grey literature databases on SCS that incorporate non-injection routes of consumption. We screened 22,882 titles, and excluded 22,843 (99.8\%) articles. We ultimately included $39(0.2 \%)$ full-text articles; 28 (72\%) of these articles explicitly identified SCS that permit alternate routes of consumption and 21 (54\%) discussed characteristics of participants who consume drugs through noninjection routes. Data on study characteristics, terms and definitions, and site and program participant characteristics were extracted and double-coded. Extracted data were analyzed using descriptive statistics and narrative synthesis.

Results: Included articles describe 48 SCS that permit non-injection routes of consumption, most of which were located in Germany. The majority of these SCS were legally sanctioned and had models of care that were largely comparable to supervised injection services. Notable differences included physical infrastructure such as ventilated rooms or outdoor areas to accommodate inhalation, and shorter time limits on non-injection drug consumption episodes. Program participants engaging in non-injection forms of consumption were typically men over the age of 30 and structurally vulnerable (e.g., experiencing homelessness or unstable housing).

Conclusions: Extant academic and grey literature indicates that site characteristics and demographics of program participants of SCS that permit non-injection routes of consumption largely reflect those of supervised injection services. Further research on the range of existing SCS that incorporate non-injection routes of consumption is needed to ensure high quality service provision, and improved health outcomes for people who consume drugs via oral, intranasal, and inhalation routes.

Keywords: Supervised consumption service, Drug consumption room, Drug policy, Harm reduction, Safer inhalation

*Correspondence: ehyshka@ualberta.ca

${ }^{1}$ School of Public Health, University of Alberta, Edmonton, AB, Canada

Full list of author information is available at the end of the article permits use, sharing, adaptation, distribution and reproduction in any medium or format, as long as you give appropriate credit to the original author(s) and the source, provide a link to the Creative Commons licence, and indicate if changes were made. The images or other third party material in this article are included in the article's Creative Commons licence, unless indicated otherwise in a credit line to the material. If material is not included in the article's Creative Commons licence and your intended use is not permitted by statutory regulation or exceeds the permitted use, you will need to obtain permission directly from the copyright holder. To view a copy of this licence, visit http://creativecommons.org/licenses/by/4.0/. The Creative Commons Public Domain Dedication waiver (http://creativeco mmons.org/publicdomain/zero/1.0/) applies to the data made available in this article, unless otherwise stated in a credit line to the data. 


\section{Introduction}

Supervised consumption services (SCS) “...are protected places used for the hygienic consumption of preobtained drugs in a non-judgemental environment and under the supervision of trained staff" [1] (p. 2). As of December 2018, there were 117 SCS operating globally [2]. Studies of SCS demonstrate that monitoring injection drug consumption reduces overdose risk and other negative health outcomes, helps connect people to health and social services, and can contribute to reductions in improperly discarded syringes and other public disorder [3, 4]. However, the majority of scientific literature on SCS is derived from two facilities: Insite in Vancouver, Canada and the Medically Supervised Injecting Centre in Sydney, Australia which are targeted specifically for people who inject drugs $[3,4]$. Much less is known about the practice of supervising non-injection forms of consumption and SCS models that accommodate people taking drugs by oral, intranasal, and inhaled routes. This is problematic because people who inject drugs are only a subsection of the overall population of people who use illegal drugs. Globally, out of approximately 100 million people who consumed opioids, amphetamines, and cocaine in 2016/2017, only 11 million consumed their drugs through injection [5].

Injection is typically the riskiest route of illegal drug administration, and people who inject drugs have an amplified risk of human immunodeficiency virus (HIV), hepatitis $\mathrm{C}$, and overdose compared to those who consume drugs via non-injection routes [6]. Nevertheless, many people who take drugs by non-injection routes of consumption still experience harm. Fatal overdoses associated with illegal drug consumption by inhalation, intranasal, and oral routes have been documented in multiple settings [6-8]. In Canada and the USA, widespread contamination of the illegal drug market with clandestinelyproduced synthetic opioids [9] has increased the risk of overdose for people who consume drugs via non-injection routes $[10,11]$. Beyond overdose, evidence suggests that, when shared, pipes used for drug inhalation are a potential vector for hepatitis $C$ transmission [12, 13], as is shared equipment for intranasal consumption (e.g., straws) [13]. Smoking drugs may also increase a person's risk of HIV seroconversion [14], though the specific mechanisms for this association remain unclear. People engaged in public non-injection drug consumption report experiencing violence when using in public areas, from police and others $[15,16]$. SCS that incorporate non-injection routes of consumption have the potential to reduce the risk of these harms through provision of emergency medical care, a safe environment, and sterile smoking and intranasal consumption supplies [17-20]. Additionally, providing access to SCS that incorporate non-injection routes of consumption may reduce the risk of transitioning to injection [21]. Prior research suggests that contact with health services can help reduce transitions from intranasal consumption to injection [22]. Harm reduction education from trained SCS staff could also help support people who inject drugs in transitioning to less risky modes of consumption. Excluding noninjection routes of drug consumption from SCS may undermine harm reduction efforts and expose people who use illegal drugs to preventable harms.

While the characteristics of people who consume drugs through non-injection routes of consumption have been described [23-26], less is known about the subpopulation of people who access SCS for oral, intranasal, or inhaled drug use. Recent evidence from a supervised consumption service in Canada demonstrated that program participants were predominantly Indigenous, male, and between the ages of 20-39 [17]. Whether these demographic characteristics are consistent in other SCS that offer non-injection routes of consumption is currently unknown. Many SCS in Europe permit non-injection routes of drug consumption [27] and SCS in North America are increasingly incorporating alternate routes of consumption. However, a comprehensive understanding of the characteristics of these SCS is lacking, potentially hindering the implementation of SCS for individuals who use non-injection routes of consumption. To address this gap, we conducted a systematic scoping review of the peer-reviewed and grey literature to describe the extent to which SCS monitor non-injection routes of drug consumption. Our specific objectives were to (1) identify SCS that incorporate non-injection routes of illegal drug consumption; (2) describe the service models and the characteristics of people who use SCS for inhalation, oral, or intranasal substance use; and (3) outline existing knowledge gaps on supervising noninjection routes of consumption to facilitate implementation and evaluation of new SCS models that meet the needs of all people who use illegal drugs.

\section{Methods}

Our study design was adapted from the scoping review framework outlined by Arksey and O'Malley [28], and we report our results using the PRISMA Extension for Scoping Reviews (PRISMA-ScR) checklist [29]. No formal study protocol was published prior to conducting this study.

\section{Search strategy}

There is no standard nomenclature for describing SCS in the literature. Accordingly, we developed a broad search strategy to capture all possible English terms used to describe these services in peer-reviewed and 
grey literature. Team members with detailed knowledge of harm reduction research developed the search terms, which were verified by an external expert with clinical and scientific expertise in the area. We conducted a pilot search, which helped us refine our search terms. SC further refined these terms, and executed a search on the peer-reviewed databases outlined in Table 1 using controlled vocabulary (e.g., MeSH, Emtree, etc.) and key words representing the concepts "supervised drug consumption" and "safer smoking" on September 12, 2017. No other limits were applied. The detailed search strategy applied to OVID Medline is available in Table 2 (see Additional file 1 for the remaining database search strategies). KS searched the first 10 pages of the grey literature

Table 1 Resources searched in the scoping review

\begin{tabular}{ll}
\hline Peer-reviewed database & Grey literature \\
\hline OVID Medline (1946-current) & Google \\
OVID EMBASE (1974-current) & Google Scholar \\
OVID PsycINFO (1806-current) & International Network of Drug Consumption Rooms \\
EBSCO CINAHL & European Monitoring Centre for Drugs and Drug Addiction \\
PROSPERO & Archiv-lt \\
Proquest Dissertations and Theses Global & Health Systems Evidence \\
Web of Science (SciEXPANDED) & Leading Practices Database \\
Cochrane Central Register of Controlled Trials & Harm Reduction International \\
Cochrane Database of Systematic Reviews & Bielefeld Academic Search Engine \\
& Grey Literature Report \\
& WorldCat \\
& AMICUS \\
\hline
\end{tabular}

\section{Table 2 Search strategy used for OVID Medline}

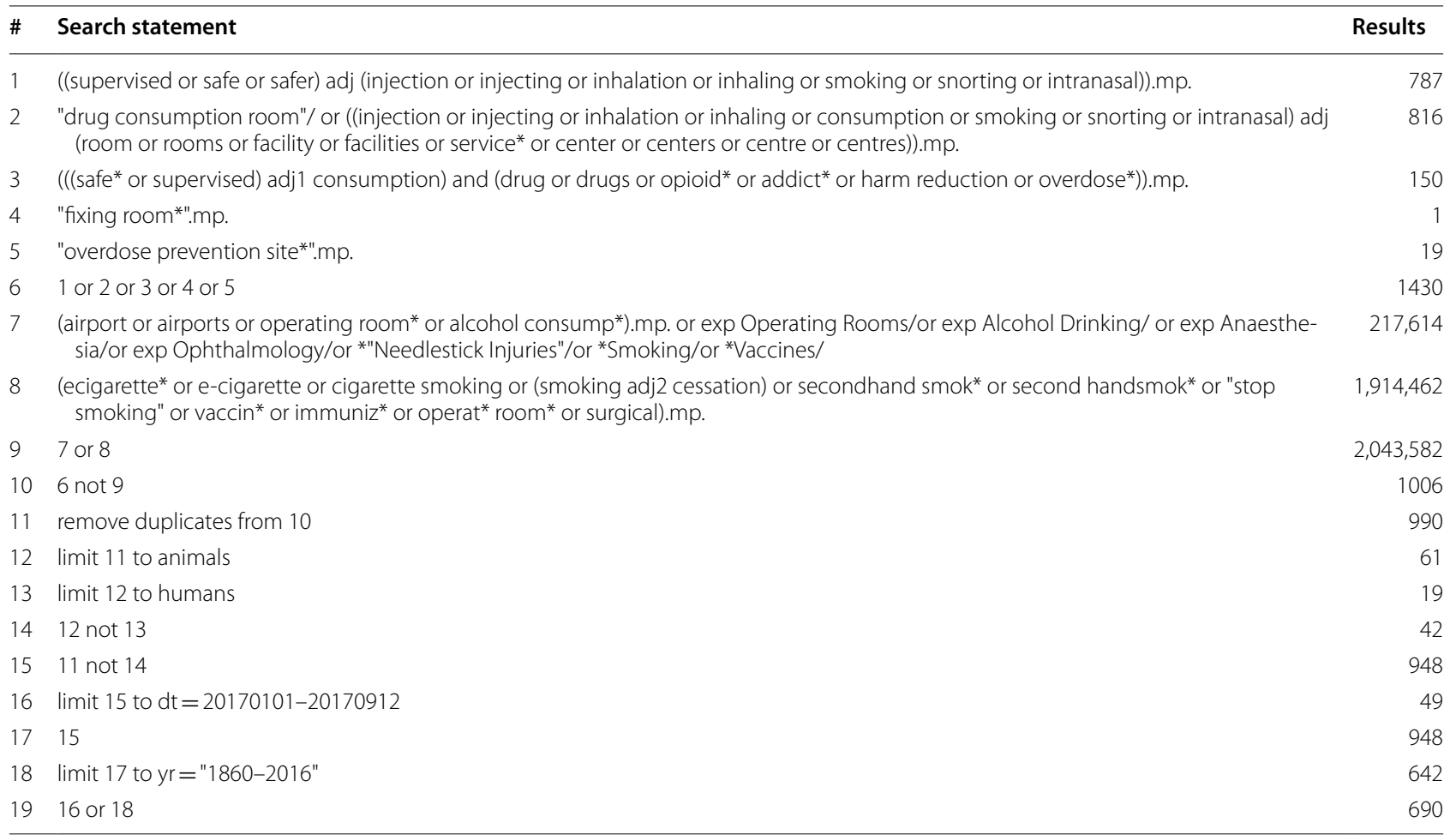


resources outlined in Table 1 for any relevant articles available in English between October 4 and December 22, 2017. A list of key terms adapted from the peer-reviewed search strategy is provided in Additional file 2.

We assessed the final search results against a list of exemplar articles provided in Additional file 3 to verify the scope of the search strategy. All of the articles except one commentary [21] were identified through the search of peer-reviewed databases. Collins et al. (2005) [21] was identified during a hand search of the reference lists of included articles, despite ultimately being excluded from the review based on the article type (an exclusion criterion; Table 3). Therefore, we believe our search strategy was sufficiently comprehensive to address our objectives.

\section{Screening}

We managed the articles from the peer-reviewed database search in RefWorks $(n=2619)$, and removed duplicates. We then transferred the remaining articles to Covidence, which is a Cochrane Collaboration recommended systematic review platform, where we removed more duplicates prior to screening (1213 total duplicates removed). KS and one of KL and NG independently screened the peer-reviewed literature by assessing the title and abstract of each article $(n=1552)$, followed by the full text article $(n=807)$, against the inclusion and exclusion criteria provided in Table 3.

KS identified potentially relevant articles during the grey literature search, and KS, DOB, and HB screened the title, abstract, and/or full-text $(n=4799)$ against the same inclusion and exclusion criteria as the peerreviewed literature. As texts available through the grey literature search often did not provide an abstract, we did not conduct two-step screening as we did with the peerreviewed literature. Each article was assessed by one of $\mathrm{KS}$, DOB, or HB.

KS and AP cross-checked three external reference lists related to SCS for any potentially relevant articles that were not captured in the peer-reviewed databases and grey literature searches. These reference lists each consisted of a collection of articles related to SCS that were compiled by external organizations, and were not considered articles in-and-of themselves. KS, DOB, and NG hand searched the bibliographies of the included studies for any potentially relevant articles that were not captured previously.

This manuscript describes a subset of the articles that discuss SCS that permit non-injection routes of consumption. To establish this subset of articles, KS and NG screened the full-text articles by independently assessing them against the following inclusion criteria: (1) at least one SCS was identified by name as incorporating noninjection routes of consumption; and (2) information was provided about characteristics of program participants who use drugs orally, intranasally, or by inhalation by describing this subpopulation separately from those who inject drugs, or by clarifying that participant characteristics were the same across modes of drug consumption (without necessarily identifying the SCS by name as incorporating non-injection routes of consumption).

Any discrepancies in screening were discussed among the reviewers, and KS made the final decision in consultation with $\mathrm{EH}$ on any articles that did not clearly fit within either the inclusion or exclusion criteria. Reasons for exclusion and the final number of included articles are provided in Fig. 1.

\section{Table 3 Inclusion and exclusion criteria for screening}

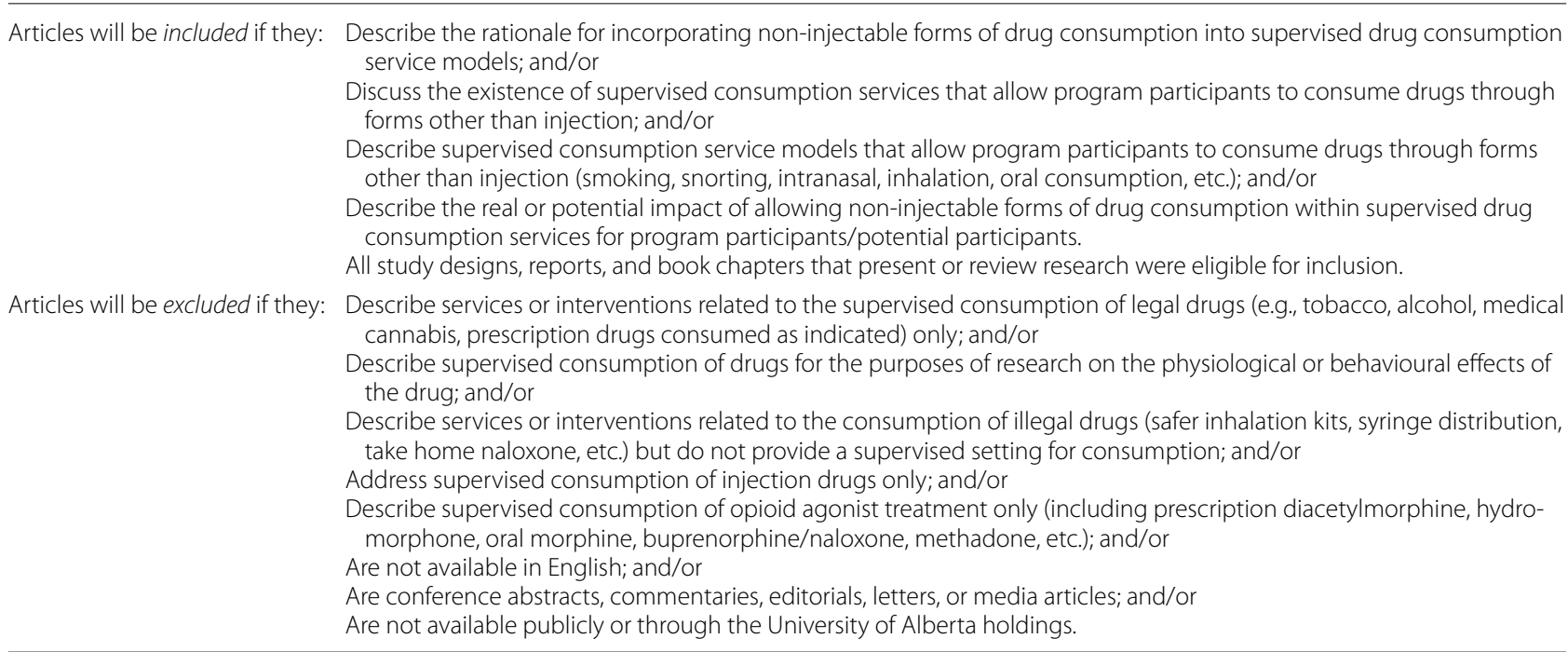




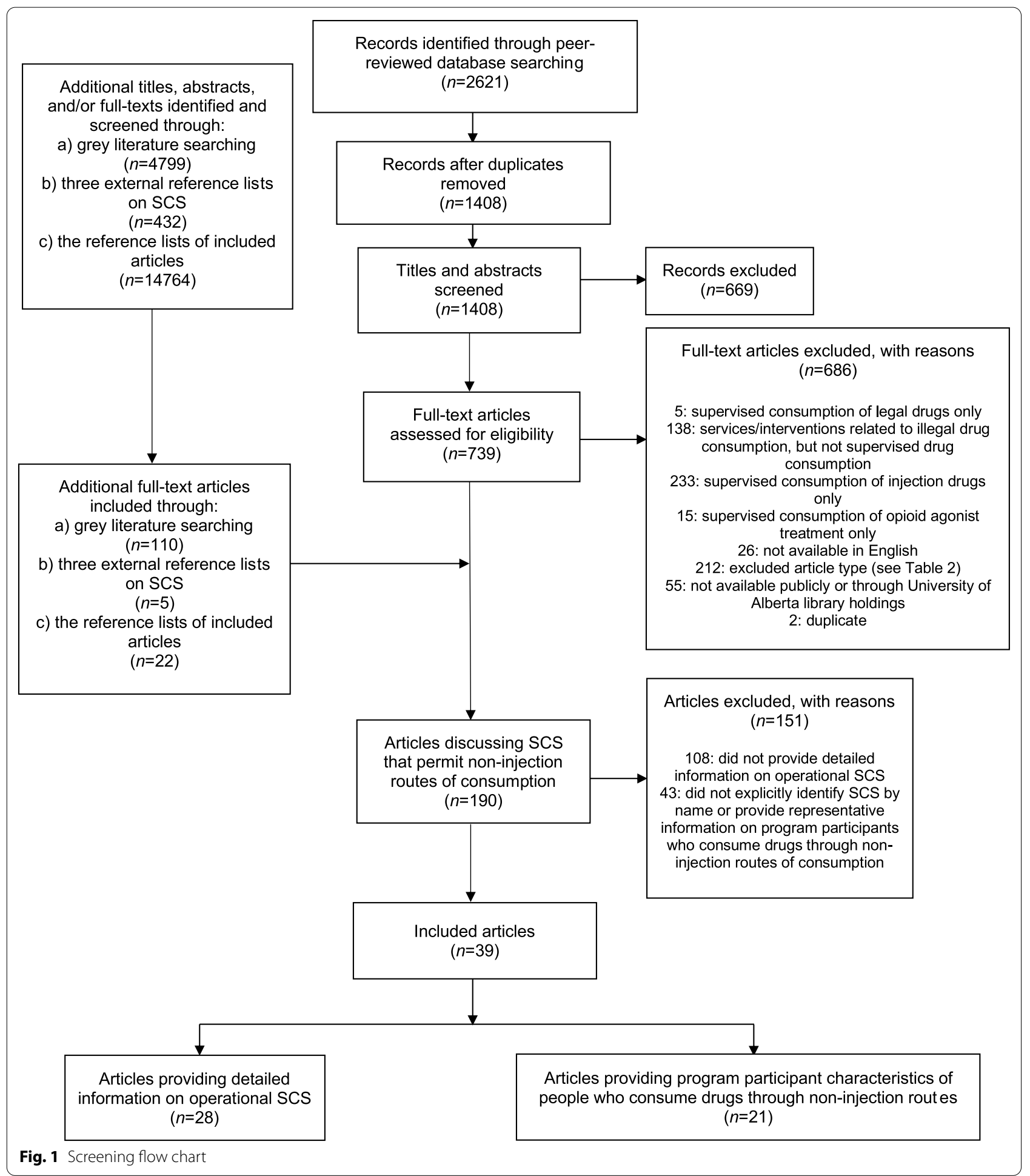




\section{Data extraction}

We developed a data extraction sheet based on the overall study objectives. KS and KL piloted the data extraction sheet by both extracting data from the same five articles. We refined the data extraction sheet in response to inconsistencies between coders. KS and KL then recoded the same five articles and revised the variable definitions as required until we reached a consensus on the data extraction for these five articles. KS and KL then coded another 10 articles in order to finalize the data extraction sheet. The following data was extracted for each article: study characteristics (title, author(s), year of publication, home country of lead author, study design, and data type), SCS terms and definitions, SCS site characteristics (location, name, legal status, consumption route, model, layout, hours, staffing, rules and eligibility criteria, target population, number of visitors, services provided, and operational costs), and program participant characteristics (age, gender/sex, ethnicity, length of drug use, housing status). KS, KL, DOB, and NG doublecoded the remaining included articles (two coders independently extracted data for each article). The coders discussed any disagreements in coding until a consensus was reached. If the two coders were unable to reach a consensus, a third team member was consulted and made the final decision.

\section{Data analysis}

KS conducted the analysis of the extracted data using Microsoft Excel for Mac, Version 15.32, using descriptive statistics (counts and frequencies) to summarize patterns across studies, and narrative synthesis to summarize the extracted text. Narrative synthesis is particularly useful when the objectives, methods, and synthesis provided by the included articles are heterogeneous [30]. We adapted the narrative synthesis protocol for systematic reviews developed by Popay et al. (2006) by applying two of their identified steps, "developing a preliminary synthesis" and "exploring relationships in the data" (p.12). The other two steps, "developing a theoretical model of how the interventions work, why and for whom" and "assessing the robustness of the synthesis product" (p. 12), were not relevant to the objectives of the present study. NG verified the accuracy of the analysis.

\section{Included articles}

Figure 1 details the literature screening process (further detail is provided in Additional file 4). Overall, our scoping review identified 193 articles that mentioned supervising non-injection routes of drug consumption in some capacity; we ultimately included 39 articles that met our objectives for this analysis. Of the included articles, 28 (72\%) identified at least one SCS supervising non-injection routes of consumption, and 21 articles (54\%) provided program participant characteristics.

Of the 39 included articles, over half were considered "grey" literature $(n=23 ; 59 \%)$, and the remaining articles were peer-reviewed literature $(n=16 ; 41 \%)$. Half of the included articles were non-empirical and provided neither qualitative nor quantitative data $(n=21$; $54 \%$ ), while the remaining articles provided qualitative data $(n=6 ; 15 \%)$, quantitative data $(n=9 ; 23 \%)$, or both qualitative and quantitative data $(n=3 ; 8 \%)$. Additional file 5 details the included articles on identified SCS that incorporate alternative routes of consumption, and Additional file 6 provides information on the included articles providing representative data on program participant characteristics.

\section{Results}

There were many terms used in the included articles to discuss formal spaces where people can consume illegal drugs via non-injection routes under the supervision of trained staff, and these terms were often used interchangeably in the literature. Overall, 65 unique terms were used throughout the 39 articles included in this study. "Drug consumption room" was the term used the most frequently $(n=22)$, followed by "supervised injection facility" $(n=10)$, "consumption room" $(n=10)$, and "drug consumption facility" $(n=9)$. Other terms, such as "supervised inhalation facility," "drug assistance service," and "overdose prevention site" were also used.

\section{Characteristics of existing SCS}

Twenty-eight articles identified 48 specific SCS as supervising non-injection routes of consumption (see Fig. 2 for global distribution). The location of each identified SCS is provided in Table 4 by country, city, and service name. Of these SCS, 47 (98\%) permitted inhalation, 45 (94\%) permitted injection, 12 (25\%) permitted intranasal consumption, and no SCS were clearly identified as permitting oral consumption. Note that given the information provided in each article, it was not always possible to identify with certainty whether a specific SCS accommodated a specific mode of drug consumption.

Of the 48 identified SCS that permitted non-injection routes of consumption, 42 (88\%) were considered legally sanctioned, $5(10 \%)$ were identified as unsanctioned, and the legal status for 1 SCS (2\%) was not described. The unsanctioned SCS that allowed non-injection routes of consumption were all located in either Australia or Canada, while the sanctioned SCS that allowed alternate routes of consumption were in Europe.

The specific service model was detailed for 45 (94\%) of the identified SCS. Forty SCS (89\%) were described as integrated models, defined as: "... SCSs [that] are part 


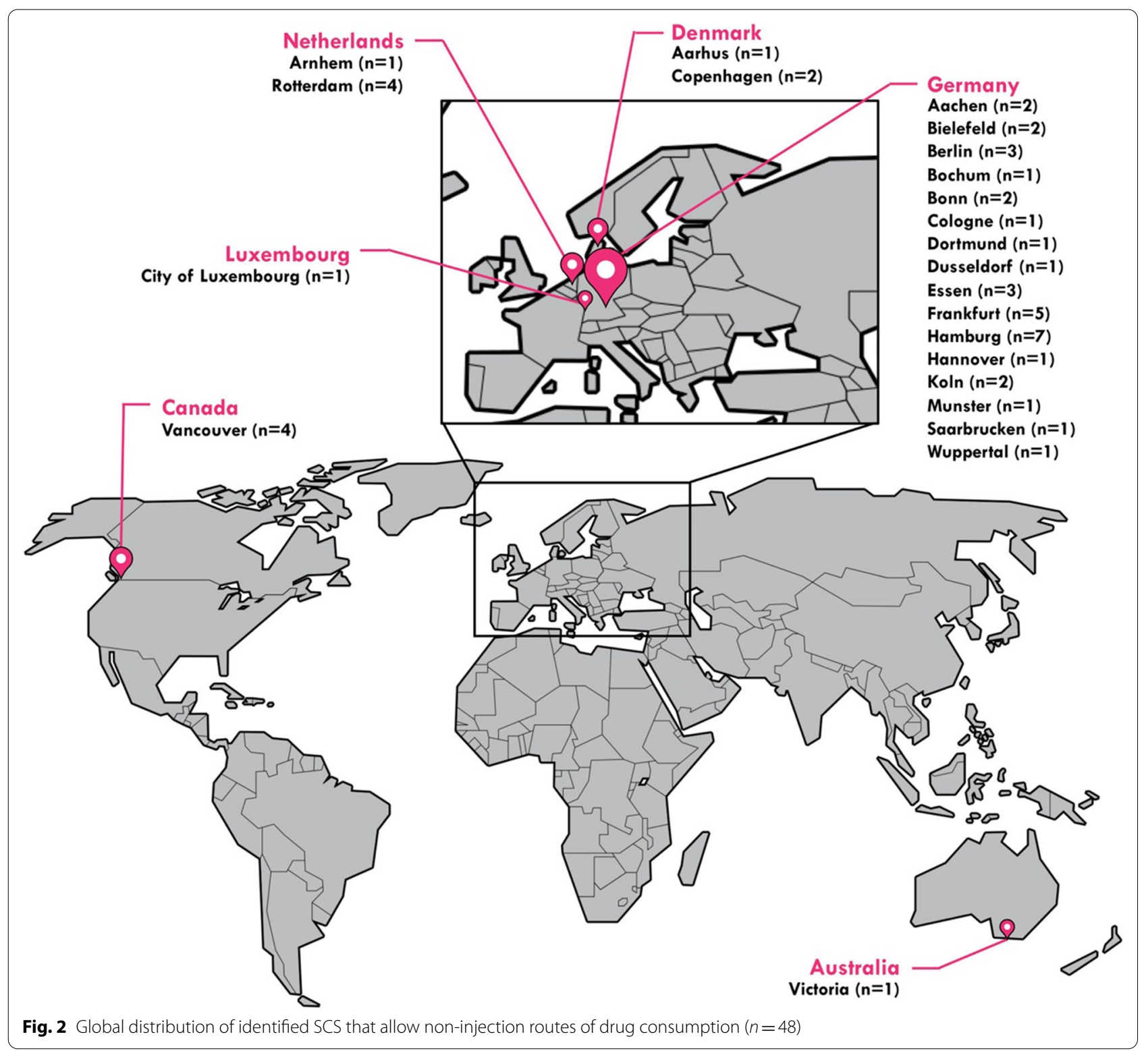

of larger facilities that offer an array of different services, typically to clients who are unstably housed and/ or who inject drugs. Integrated facilities aim to provide comprehensive health and medical care, as well as social services, as a "one-stop-shop" for harm reduction and health care services" [31] (p.14). Three SCS (7\%) were identified as 'specialized' SCS, which Kerr et al. (n.d.) [31] define as "... a distinct facility that is dedicated to providing SCS. ... This type of facility may offer other additional services, such as showers, refreshments, meals, primary care services, counselling, and temporary housing (i.e., shelter). ... However, the majority of the facility's staff time and resources are dedicated to the operations of the
SCS program" (p. 13). Two SCS were mobile, which Kerr et al. (n.d.) [31] describe as "... [consisting] of modified vans or buses that contain injection booths and that can be moved to locations where public drug activities occur" (p. 15).

The layout of the SCS was also provided for these 45 SCS (Table 5). Intranasal consumption could occur separately, but often occurred in the inhalation areas or injection spaces. Articles explicitly stated that 6 SCS (13\%) allowed visitors to inhale drugs in a separate, often ventilated, room; and 4 SCS (9\%) allowed visitors to inhale drugs in an outdoor setting. Articles typically indicated that the SCS included more injection than inhalation 
Table 4 Location of identified SCS that allow non-injection routes of consumption

\begin{tabular}{|c|c|c|c|}
\hline Country & City & Name & Citation(s) \\
\hline Australia & Victoria & Berry Street & {$[56,86]$} \\
\hline \multirow[t]{4}{*}{ Canada } & Vancouver & 327 Carrall Street SIS & [79] \\
\hline & & Dr. Peter Centre Residence & [77] \\
\hline & & Pop-up SIS & {$[87]$} \\
\hline & & VANDU's unsanctioned inhalation facility & {$[15,16,41,87]$} \\
\hline \multirow[t]{3}{*}{ Denmark } & Aarhus & Aarhus DCR & {$[36,78]$} \\
\hline & Copenhagen & Maendenes Hjem & {$[88]$} \\
\hline & & Skyen & {$[36,44,53,78]$} \\
\hline \multirow[t]{34}{*}{ Germany } & Aachen & Drogenhilfe Aachen & [33] \\
\hline & & Suchthlife Aachen & [43] \\
\hline & Bielefeld & Bielefeld DCR & [45] \\
\hline & & Drogenberatung Bielefeld e.V. & [43] \\
\hline & Berlin & Birkenstube & [43] \\
\hline & & Fixpunkt & [43] \\
\hline & & SKA & [45] \\
\hline & Bochum & Krisenhilfe Bochum & [43] \\
\hline & Bonn & DCR Bonn & [44] \\
\hline & & Verein fur Gefahrdetenhilfe & [43] \\
\hline & Cologne & Kontaktstelle fur Drogenabhangige & [33] \\
\hline & Dortmund & KICK-Aide-Hilfe & {$[43,45]$} \\
\hline & Dusseldorf & Dusseldorfer Drogenhilfe e.V. & [43] \\
\hline & Essen & Krisenhilfe Essen & [33] \\
\hline & & Suchthilife direkt Essen & [43] \\
\hline & & The Essen DCR & [89] \\
\hline & Frankfurt & Drogennotdienst Frankfurt & [43] \\
\hline & & Eastside & [43] \\
\hline & & Elbestraße & {$[50]$} \\
\hline & & La Strada & {$[43,45]$} \\
\hline & & Nidda 49 & {$[43,45]$} \\
\hline & Hamburg & Abrigado & {$[33,38]$} \\
\hline & & DroBill & {$[33,38]$} \\
\hline & & Drob Inn & {$[33,38,42,43]$} \\
\hline & & Fixstern & {$[33,38,42]$} \\
\hline & & Kodrobs Altona & [43] \\
\hline & & Ragazza e.V. & {$[33,38,43-45]$} \\
\hline & & Stay Alive & {$[33,38,42,43]$} \\
\hline & Hannover & Fixpunkt/Step gGmbH & [43] \\
\hline & Koln & KAD I & [43] \\
\hline & & KAD \| & [43] \\
\hline & Munster & Indro & {$[33,37,38,43]$} \\
\hline & Saarbrucken & Drogenhilfezentrum Saarbrucken gGmbH & [43] \\
\hline & Wuppertal & Gleis 1 & {$[33,43]$} \\
\hline Luxembourg & City of Luxembourg & Abrigado & {$[1,46,90,91]$} \\
\hline \multirow[t]{5}{*}{ Netherlands } & Arnhem & Stichting Gelders Centrum Voor Verslavingszorg & {$[34,35]$} \\
\hline & Rotterdam & Buurthuis & [32] \\
\hline & & Keetje Tippel & {$[32]$} \\
\hline & & Moerkerkestraat & {$[32]$} \\
\hline & & Pauluskerk & {$[32,34]$} \\
\hline
\end{tabular}


Table 5 Layout of identified SCS that allow non-injection routes of consumption

\begin{tabular}{|c|c|c|c|}
\hline Country & Name & Layout & Citation \\
\hline Australia & Berry Street & Backyard of residential facility & {$[56]$} \\
\hline \multirow[t]{6}{*}{ Canada } & 327 Carrall Street SIS & $\begin{array}{l}\text { Storefront space with a back room with two small tables divided by a tem- } \\
\text { porary wall for injection and washroom; after four months, visitors were } \\
\text { allowed to consume via inhalation in the washroom with a fan }\end{array}$ & {$[79]$} \\
\hline & Dr. Peter Centre Residence & $\begin{array}{l}\text { Injection within residents' rooms and inhalation accommodated in an } \\
\text { outside area }\end{array}$ & {$[77]$} \\
\hline & Pop-up SIS & Tables within a tent & {$[87]$} \\
\hline & \multirow[t]{3}{*}{ VANDU's unsanctioned inhalation facility } & Bathroom with ventilation system & {$[15]$} \\
\hline & & Inhalation room with fan accessible to one person at a time & {$[41]$} \\
\hline & & $\begin{array}{l}\text { Storefront location with a lobby, front desk area, injection room, and small } \\
\text { adapted washroom with ventilation system accessible to one person at a } \\
\text { time }\end{array}$ & {$[16]$} \\
\hline \multirow[t]{7}{*}{ Denmark } & \multirow[t]{2}{*}{ Aarhus DCR } & 5 spaces for injection and 2 spaces for inhalation & {$[78]$} \\
\hline & & Injection room, smoking room, health clinic & {$[36]$} \\
\hline & Maendenes Hjem & $\begin{array}{l}\text { Various rooms for different purposes including an injection and smoking } \\
\text { room }\end{array}$ & {$[88]$} \\
\hline & \multirow[t]{4}{*}{ Skyen } & Spaces for injection and inhalation (air conditioned) & {$[53]$} \\
\hline & & 8 spaces for injection and 6 spaces for inhalation & {$[78]$} \\
\hline & & 7 spaces for inhalation & {$[44]$} \\
\hline & & Booths for injection and a separate room for inhalation & {$[36]$} \\
\hline \multirow[t]{23}{*}{ Germany } & \multirow[t]{2}{*}{ Abrigado } & 4 spaces for injection and 4 spaces for inhalation & {$[38]$} \\
\hline & & $\begin{array}{l}10 \text { rooms for different purposes; } 4 \text { spaces for injection and } 4 \text { spaces for } \\
\text { inhalation }\end{array}$ & {$[33]$} \\
\hline & Birkenstube & 6 spaces for injection/intranasal and 4 spaces for inhalation & {$[43]$} \\
\hline & DCR Bonn & $\begin{array}{l}\text { Ground floor: care area with lounge and kitchen } \\
\text { First floor: counselling centre for drug use } \\
\text { Second floor: medical clinic (outpatient) } \\
\text { Third floor: crisis intervention (inpatient; short term; maximum } 6 \text { clients) } \\
\text { Backyard: } 5 \text { spaces for injection and } 3 \text { spaces for inhalation }\end{array}$ & {$[44]$} \\
\hline & \multirow[t]{4}{*}{ Drob Inn } & 10 spaces for injection and 5 spaces for inhalation/intranasal & {$[43]$} \\
\hline & & 7 spaces for injection and 3 spaces for inhalation & {$[38]$} \\
\hline & & $\begin{array}{l}15 \text { rooms for different purposes; } 7 \text { spaces for injection and } 3 \text { spaces for } \\
\text { inhalation }\end{array}$ & {$[33]$} \\
\hline & & 7 spaces for injection and 3 spaces for inhalation & {$[42]$} \\
\hline & \multirow[t]{2}{*}{ DroBill } & 6 spaces for injection and 1 space for inhalation & {$[38]$} \\
\hline & & $\begin{array}{l}8 \text { rooms for different purposes; } 8 \text { spaces for injection and } 1 \text { space for inhala- } \\
\text { tion }\end{array}$ & {$[33]$} \\
\hline & Drogenberatung Bielefeld e.V. & 8 spaces for injection/intranasal and 8 spaces for inhalation & {$[43]$} \\
\hline & Drogenhilfe Aachen & $\begin{array}{l}\sim 14 \text { rooms for different purposes; } 2 \text { spaces for injection and } 2 \text { spaces for } \\
\text { inhalation }\end{array}$ & {$[33]$} \\
\hline & Drogenhilfezentrum Saarbrücken gGmbH & 13 spaces for injection/intranasal and 3 spaces for inhalation & {$[43]$} \\
\hline & Drogennotdienst Frankfurt & 10 spaces for injection/intranasal and 5 spaces for inhalation & {$[43]$} \\
\hline & Düsseldorfer Drogenhilfe e.V. & 6 spaces for injection/intranasal and 3 spaces for inhalation/intranasal & {$[43]$} \\
\hline & Eastside & 8 spaces for injection/intranasal; 2 of those spaces are for inhalation & {$[43]$} \\
\hline & Fixpunkt & 2 mobile consumption rooms; 3 spaces for injection/intranasal & {$[43]$} \\
\hline & Fixpunkt/Step gGmbH & 9 spaces for injection and 3 spaces for intranasal & {$[43]$} \\
\hline & \multirow[t]{3}{*}{ Fixstern } & 6 spaces for injection and 3 spaces for inhalation & {$[38]$} \\
\hline & & $\begin{array}{l}\text { } 10 \text { rooms for different purposes; } 6 \text { spaces for injection and } 3 \text { spaces for } \\
\text { inhalation }\end{array}$ & {$[33]$} \\
\hline & & 6 spaces for injection and 3 spaces for inhalation & {$[42]$} \\
\hline & \multirow[t]{2}{*}{ Gleis 1} & 5 spaces for injection and 4 spaces for inhalation & {$[43]$} \\
\hline & & $\begin{array}{l}\text { } 16 \text { rooms for different purposes; } 5 \text { spaces for injection and } 3 \text { spaces for } \\
\text { inhalation }\end{array}$ & [33] \\
\hline
\end{tabular}


Table 5 (continued)

\begin{tabular}{|c|c|c|c|}
\hline Country & Name & Layout & Citation \\
\hline & \multirow[t]{4}{*}{ Indro } & 4 spaces for injection/intranasal and 1 space for inhalation & {$[43]$} \\
\hline & & $\begin{array}{l}6 \text { spaces for injection (no booth-like partitions, only } 4 \text { participants at a time) } \\
\text { and one booth with air exhaust for inhalation }\end{array}$ & {$[37]$} \\
\hline & & 4 spaces for injection (maximum 6 participants) and 1 space for inhalation & {$[38]$} \\
\hline & & $\begin{array}{l}\text { } 9 \text { rooms for different purposes; 4-6 spaces for injection and } 1 \text { space for } \\
\text { inhalation }\end{array}$ & [33] \\
\hline & KADI & 3 spaces for injection/intranasal/inhalation & {$[43]$} \\
\hline & KAD \| & 6 spaces for injection/intranasal and 2 spaces for inhalation & {$[43]$} \\
\hline & KICK-Aide-Hilfe & 8 spaces for injection and 8 spaces for inhalation/intranasal & {$[43]$} \\
\hline & Kodrobs Altona & 4 spaces for injection and 2 spaces for inhalation/intranasal & {$[43]$} \\
\hline & Kontaktstelle für Drogenabhängige & $\begin{array}{l}\text { } 14 \text { rooms for different purposes; } 2 \text { spaces for injection and } 1 \text { space for } \\
\text { inhalation; smallest facility in Germany at the time }\end{array}$ & {$[33]$} \\
\hline & Krisenhilfe Bochum & 5 spaces for injection/intranasal and 3 spaces for inhalation & {$[43]$} \\
\hline & Krisenhilfe Essen & $\begin{array}{l}\text { 30 rooms for different purposes; } 8 \text { spaces for injection and } 4 \text { spaces for } \\
\text { inhalation }\end{array}$ & {$[33]$} \\
\hline & La Strada & 7 spaces for injection/intranasal & {$[43]$} \\
\hline & Nidda 49 & 12 spaces for injection/intranasal/inhalation & {$[43]$} \\
\hline & \multirow[t]{3}{*}{ Ragazza e.V. } & $\begin{array}{l}4 \text { spaces for injection/intranasal and } 6 \text { spaces for inhalation ( } 8 \text { parallel } \\
\text { consumptions maximum) }\end{array}$ & {$[43]$} \\
\hline & & 6 spaces for injection and 2 spaces for inhalation & {$[38]$} \\
\hline & & $\begin{array}{l}10 \text { rooms for different purposes; } 5 \text { spaces for injection and } 3 \text { spaces for } \\
\text { inhalation }\end{array}$ & [33] \\
\hline & \multirow[t]{4}{*}{ Stay Alive } & 8 spaces for injection, inhalation, and intranasal & {$[43]$} \\
\hline & & 6 spaces for injection and 2 spaces for inhalation & {$[38]$} \\
\hline & & $\begin{array}{l}\text { } 13 \text { rooms for different purposes; } 6 \text { spaces for injection and } 2 \text { spaces for } \\
\text { inhalation }\end{array}$ & {$[33]$} \\
\hline & & 6 spaces for injection and 2 spaces for inhalation & {$[42]$} \\
\hline & Suchthilfe direkt Essen & 8 spaces for injection/intranasal and 5 spaces for inhalation & {$[43]$} \\
\hline & Suchthlife Aachen & 5 spaces for injection; 2 of which are for inhalation & {$[43]$} \\
\hline & The Essen DCR & 8 spaces for injection and 4 spaces for inhalation & {$[89]$} \\
\hline & Verein für Gefährdetenhilfe & 5 spaces for injection/intranasal and 3 spaces for inhalation & {$[43]$} \\
\hline \multirow[t]{4}{*}{ Luxembourg } & \multirow[t]{4}{*}{ Abrigado } & Injection room and inhalation room (which opened in 2012) & {$[90]$} \\
\hline & & Injection room with 8 tables and inhalation room with 6 tables & {$[46]$} \\
\hline & & $\begin{array}{l}7 \text { spaces for injection and 3-4 spaces for inhalation (pilot project; February } \\
\text { 2012) }\end{array}$ & {$[1]$} \\
\hline & & Supervised injection and inhalation room & {$[91]$} \\
\hline \multirow[t]{6}{*}{ Netherlands } & Buurthuis & 5-6 spaces for injection and 10-14 spaces for inhalation & {$[32]$} \\
\hline & Keetje Tippel & 5 spaces for injection and 14 spaces for inhalation & {$[32]$} \\
\hline & Moerkerkestraat & 5-6 spaces for injection and 10-14 spaces for inhalation & {$[32]$} \\
\hline & \multirow[t]{2}{*}{ Pauluskerk } & $\begin{array}{l}\text { Various rooms for different purposes; } 1 \text { space for injection ( } 2 \text { tables for } 6 \\
\text { participants at a time) and } 1 \text { space for inhalation (each space } \sim 3 \times 5 \mathrm{~m} \text { ) }\end{array}$ & {$[34]$} \\
\hline & & 20 spaces for injection and 20 spaces for inhalation & {$[32]$} \\
\hline & Stichting Gelders Centrum Voor Verslavingszorg & $\begin{array}{l}\text { Entry controlled by worker in a small office inside the front door; large open } \\
\text { sitting/recreation area space }(10 \times 8 \mathrm{~m}) ; 1 \text { space for injection and } 1 \text { space } \\
\text { for inhalation regulated by staff member (both rooms } 2 \times 3 \mathrm{~m} \text {; } 8 \text { people } \\
\text { at a time; } 1 \mathrm{~m} \text { square window in doors for observation) }\end{array}$ & {$[34]$} \\
\hline
\end{tabular}

spaces; with the exception of literature from the Netherlands which suggested that more spaces for inhalation than injection were provided [32].

Articles provided the hours of operation for half $(n=24 ; 50 \%)$ of the identified SCS that permit non-injection routes of consumption, with hours ranging from as few as $3 \mathrm{~h}$ per day to as many as $24 \mathrm{~h}$ per day. While some SCS were only open on select days, others were open seven days a week. Operational hours were often dependent on funding and the staffing complement. 
In total, articles provided details on staffing for 41 (85\%) of the identified SCS that permit alternate routes of consumption. Of these 41 SCS, 35 (85\%) discussed employing healthcare professionals (e.g., nurses, physicians), 16 (39\%) discussed employing social workers, 27 (66\%) discussed employing counsellors, 2 (5\%) discussed employing peer workers (“...members of the community who have experience in safe illicit drug practices" [15]), and 35 (85\%) discussed employing other staff (e.g., outreach workers, security guards, volunteers). Both of the SCS that employ peer workers were in Canada.

Thirty-eight (79\%) of the identified SCS provided eligibility criteria for entry into SCS. Common eligibility criteria included a minimum age for entry $(n=27 ; 71 \%)$, having an active or long history of illegal drug use (i.e., not consuming illegal drugs for the first time; $n=32$; $84 \%$ ), and not being intoxicated at the time of entry $(n=15 ; 39 \%)$. Half of the identified SCS did not allow people who were on opioid agonist treatment to use the SCS $(n=19 ; 50 \%)$; however, in some cases conflicting information regarding this restriction was provided. Other eligibility criteria included not allowing people who were pregnant to consume drugs in the SCS $(n=3$; $8 \%$ ), and only allowing people who lived in the city of the SCS to use the site $(n=3 ; 8 \%)$. Notably, literature on the Krisenhilfe Essen SCS (Germany) indicated that it allowed people from out of town who were experiencing withdrawal to use the site on a one time basis to alleviate their symptoms [33]. Two facilities (Pauluskerk and Stichting Gelders Centrum Voor Verslavingszorg in the Netherlands) require program participants to be preapproved to use the site [34, 35]. Other rules beyond eligibility criteria included restrictions on: drug sharing $(n=31 ; 82 \%)$; reusing equipment $(n=27 ; 71 \%)$; the substances that could be consumed within the SCS $(n=8$; $21 \%)$; and the route that substances could be consumed $(n=4 ; 11 \%)$. Further, some facilities had rules prohibiting violence towards staff or other people within the SCS $(n=9 ; 24 \%)$, or banning peer assistance for drug consumption $(n=9 ; 24 \%)$.

Articles provided information on the time limits imposed on people using the consumption room for 14 of the identified SCS (37\%). These time limits most commonly ranged from 5 to $30 \mathrm{~min}$ in length $(n=8 ; 57 \%)$. Alternatively, articles that discussed the Aarhus DCR (Denmark), Buurthuis (Netherlands), and Moerkerkestraat (Netherlands) indicated that there were no time limits for consumption [32, 36], while in Pauluskerk (Netherlands) there was a time limit for inhalation but not for injection [32]. Pauluskerk (Netherlands), Keetje Tippel (Netherlands), and Indro (Germany) all had different time limits for inhalation compared to injection, with shorter time limits imposed on those inhaling their drugs [32, 37]. Finally, Stoever [38] stated that Abrigado, Ragazza e.V., and Drobill in Germany enforced a time limit in the consumption rooms without specifying the length.

Articles discussed the services provided at 45 of the identified SCS (94\%). Forty-two (93\%) SCS provided social services (e.g., referrals to substance use disorder treatment programs); 42 (93\%) provided health services (e.g., HIV testing, medical treatment); 36 (80\%) distributed harm reduction supplies (e.g., needle exchange, condoms); 23 (51\%) provided basic needs (e.g., food, showers, laundry); 36 (80\%) provided education (e.g., safer use counselling, health education); 10 (22\%) provided shelter (e.g., overnight accommodations); and 25 (56\%) provided other services (e.g., drop-ins, referrals to further services) to program participants. However, one article discussed how the ability to provide services such as education was reduced in inhalation areas compared to the injection spaces, due to potential air quality-related occupational health and safety concerns for staff [36].

These articles further discussed the number of program participants for 20 (42\%) of the identified SCS. In general, the number of daily program participants varied depending on where the SCS was located; SCS located within a concentrated drug scene typically had a higher number of people accessing the site than SCS that were located away from areas where people who use drugs tended to spend their time [27, 39]. The number of daily program participants also varied depending on other contextual and site characteristics [40] such as the target population, service hours, and capacity of each SCS.

As shown in Table 6, only 4 articles (8\%) provided operating costs for specific SCS that allow alternative routes of consumption. Annual costs ranged from $\$ 97,203.00$ CAD (\$108,311.06 USD 2020) per year for the unsanctioned inhalation facility run by Vancouver Area Network of Drug Users in Canada [41] to $f 1,200,000.00$ NLG $(\$ 1,163,954.24$ USD 2020) per year for Pauluskerk in the Netherlands [34]. All available data extracted for each of these variables are provided for each SCS in Additional file 5 .

\section{Characteristics of program participants}

Twenty-one articles (26\%) provided demographic or other data on people who access SCS that permit noninjection routes of consumption in general (without necessarily identifying the SCS by name as incorporating non-injection routes of consumption). Some SCS targeted structurally vulnerable populations: Fixstern, Stay Alive, and Drob Inn in Germany targeted their services toward people who consumed drugs in public [42]; Ragazza e.V. (Germany) [33, 43-45] and Keetje Tippel (Netherlands) [32] targeted their services towards 
Table 6 Operational costs of SCS that allow non-injection routes of consumption

\begin{tabular}{|c|c|c|c|c|}
\hline Name (location) & Location & Operational costs as reported & Annual operational costs in USDa & Citation \\
\hline DCR Bonn, Ragazza, and Skyen & $\begin{array}{l}\text { Bonn and Hamburg, Germany } \\
\text { Copenhagen, Denmark }\end{array}$ & $\begin{array}{l}\text { Cost per participant in mobile SCS } \\
\text { higher than fixed-site SCS (less } \\
\text { visits per day yet require similar } \\
\text { staffing levels) }\end{array}$ & NA & {$[44]$} \\
\hline Indro & Munster, Germany & Annual cost: $€ 125,000.00$ & $\$ 187,488.11^{b}$ & {$[37]$} \\
\hline Pauluskerk & Rotterdam, Netherlands & Annual budget: $f 1,200,000.00$ & $\$ 1,163,954.24^{c}$ & {$[34]$} \\
\hline \multirow[t]{3}{*}{ Unsanctioned inhalation facility } & Vancouver, Canada & $\begin{array}{l}\text { Annual volunteer stipends: } \\
\$ 47,203.00 \text { CAD }\end{array}$ & $\begin{array}{l}\text { Annual volunteer stipends: } \\
\$ 64,068.74^{d}\end{array}$ & {$[41]$} \\
\hline & & $\begin{array}{l}\text { Annual rent and drug use equip- } \\
\text { ment: } \$ 50,000.00 \text { CAD }\end{array}$ & $\begin{array}{l}\text { Annual rent and drug use equip- } \\
\text { ment: } \$ 55,713.91^{d}\end{array}$ & \\
\hline & & Total annual cost: $\$ 97,203.00$ CAD & Total annual cost: $\$ 108,311.06^{\mathrm{d}}$ & \\
\hline
\end{tabular}

NA not applicable

a Exchange rates based on the first day of the month in which the article was published and then adjusted for inflation in 2020

b 1 Euro $=1.07640$ USD (2003); $\$ 134,550.00$ USD (2003)

c $1 \mathrm{NLG}=0.54666$ USD (1993); \$655,988.00 USD (1993)

d 1 CAD = 0.82095 USD (2004); annual volunteer stipend: \$38,751.40 USD (2004); annual rent and drug use equipment: \$41,047.60 USD (2004); total annual cost: $\$ 79,798.90$ USD (2004)

women, particularly sex workers; and Buurthuis and Moerkerkestraat in the Netherlands targeted people experiencing homelessness [32].

Thirteen articles $(62 \%)$ provided data on the age of program participants, and 4 articles (19\%) provided data on length of drug use history. People who use SCS that allow alternate routes of consumption were more likely to be 30 years of age or older $[1,34,39,40,46-52]$, and to have used drugs for at least 10 years [39, 40, 51]. In addition, Zobel and Dubois-Arber (2004) noted that people who used the inhalation rooms in Switzerland had a long history of drug use, and included people who had previously consumed their drugs through injection as well as those who had never injected their drugs [52].

Thirteen articles (62\%) provided information on the sex and/or gender of the program participants. Most of the sites reported seeing more men than women $[1,32,34$, 37, 40, 43, 46-51, 53] with two exceptions: (1) Keetje Tippel in the Netherlands served women who participated in sex work and only allowed women to access the SCS [32]; and (2) the 12 SCS in Germany had a higher proportion of women than men in the 18-25 year old age group between 2001 and 2009 [43].

Six articles (29\%) provided information on the ethnicity of the program participants of SCS that allow noninjection routes of consumption. The articles reported different kinds of information across the sites, making it difficult to synthesize. For example, the program participants of four SCS in the Netherlands (Pauluskerk, Keetje Tippel, Buurthuis, and Moerkerkestraat) were broken down into Dutch (45\%) and other (55\%) [32], whereas Hunt [54] stated that SCS in the Netherlands, Germany, and Switzerland saw "[a] large proportion of service users [who] appeared to come from minority ethnic groups..." (p. 10).

Ten articles (48\%) provided information on the housing status of program participants. Overall, a disproportionately large amount of participants were currently or previously living in unstable housing situations [32, 34, $39,40,48,50,53,55]$, although the proportion varied by site and location. There were two notable exceptions to this trend: (1) the program participants of the inhalation room in Biel/Bienne, Switzerland did not experience homelessness [52], and (2) all participants of the SCS at Berry Street in Victoria, Australia were residents of the facility [56]. See Additional file 6 for more detailed information on the program participant characteristics provided by each of the included articles.

\section{Discussion}

We conducted the first systematic search and synthesis of academic and grey literature on SCS that permit non-injection routes of consumption. We identified 193 articles that discussed SCS allowing alternate routes of consumption in some capacity, and ultimately included 39 articles which identified 48 SCS that permit program participants to consume orally, intranasally, or via inhalation.

While systematic reviews of SCS have been conducted in the past $[3,4,57]$, our study is the first to focus explicitly on what is known regarding the service models of SCS that accommodate drug consumption by oral, intranasal, or inhalation routes. Despite capturing 193 potentially relevant articles that discussed supervising non-injection forms of drug consumption, only 39 identified specific examples of SCS allowing alternate routes 
of consumption and/or provided program participant characteristics for people who use drugs orally, intranasally, or by inhalation. This indicates that there is limited published literature focusing specifically on this type of SCS. Some characteristics (e.g., service provision, rules and eligibility, staffing, hours, layout) are more clearly documented in the available literature than others (e.g., number of visitors, target population, operational costs), and the majority of identified SCS were located in one country (Germany; 71\%).

According to available literature, program participants were typically men over the age of 30 and part of a structurally vulnerable population (e.g., experiencing homelessness or unstable housing). This is consistent with characteristics of program participants reported in research on supervised injection services [4]. The range of site characteristics identified in our review are also largely consistent with the literature on supervised injection services (see the Medically Supervised Injecting Centre in Australia [58] for an example of a supervised injection service), which is unsurprising given the majority of identified SCS also served people who inject drugs. For example, the majority of SCS identified in this scoping review were legally sanctioned, integrated models with comparable eligibility criteria (e.g., minimum age, history of illegal drug use) and service provision (e.g., social services, harm reduction supplies, education) to supervised injection services. Notable differences between the SCS in this study compared to supervised injection services included alternative layouts to accommodate spaces for non-injection routes of consumption, primarily inhalation (i.e., ventilated rooms, outdoor areas), and shorter time limits for inhalation compared to injection. Longer time limits for injection may reflect the more extensive and time consuming drug preparation process required compared to consumption via inhalation [59]. Ultimately, it appears that integrating non-injection routes of consumption within supervised injection services does not require increased resources to implement or operate the non-injection portion of the service, beyond physical infrastructure requirements for accommodating inhalation.

Increasingly, SCS are incorporating services to address the risks associated with consuming adulterated drugs from the toxic drug supply. These services include incorporating drug checking services $[60,61]$ and the provision of pharmaceutical grade alternatives to street drugs (e.g., safe supply) [62, 63]; although these services are largely targeted to people who use opioids and often do not address the needs of people who use stimulants [64]. As these services are relatively recent developments, they were not discussed in the included articles and therefore the extent to which they are incorporated within SCS that allow non-injection routes of consumption remains unclear. However, the current emphasis on innovative solutions to the overdose crisis [65] highlights the need for SCS to be responsive to the needs of their participants. Furthermore, the current COVID-19 pandemic has also demonstrated the importance of flexibility in response to the evolving needs of SCS participants [66]. People who smoke illegal drugs may be particularly at risk for complications associated with respiratory illness [67]. Many people who use drugs have been impacted by sudden closures of their SCS due to their inability to meet public health directives $[68,69]$, while other SCS had to reduce their capacity to meet physical distancing requirements [70]. The operational characteristics of both injection and non-injection SCS should be flexible and continuously adapted to address local needs and context.

We found a range of rules and criteria across the different SCS. Many SCS enacted eligibility criteria that risk excluding the populations most in need of the service. For example, women who use drugs are more likely to experience violence and are at a higher risk of bloodborne virus infections [71], yet some SCS policies (e.g., excluding people who are pregnant or who have children with them), disproportionately impact women attempting to access SCS. Many SCS did not permit people who are younger than 18 years of age to consume drugs on site. This is problematic because youth who consume illegal drugs are at heightened risk of hazardous consumption patterns or other activities (e.g., sex work) that increase risk of exposure to blood-borne viruses [72, 73]. Excluding people who wish to access these services on the basis of age does not take into account their needs $[74,75]$, and eliminates an opportunity to improve health outcomes amongst an especially vulnerable subpopulation of people who use drugs. Furthermore, SCS typically have limited operating hours, commonly operating only during the day. Recent research indicates that program participants and consumption patterns vary according to the time of day, with an increase in vulnerable populations (e.g., women and those experiencing homelessness) and stimulant use during night hours [76]. Restricting operating hours may also increase harms to vulnerable subpopulations of people who use drugs (e.g., violence, overdose). In contrast, several SCS sought to address these service gaps by specifically targeting populations of women, including those who engage in sex work [32, 33, 44], permitting people under 18 to access the SCS [33], operating 23-24 h per day [36, 77, 78], or extending hours past midnight $[32,33,79]$.

The level of reported detail on SCS varies considerably by jurisdiction, and appears to be impacted by political climates [80]. In recent years, an increasing number of 
Canadian SCS permitted intranasal and oral consumption [81], and Lethbridge, Alberta opened the first SCS in North America to permit all routes of consumption (injection, inhalation, intranasal, oral) in February 2018 [17]. However, limited data has been published on these SCS to date [82]. This contrasts sharply with the implementation of Canada's first SCS in 2003, which was contingent on extensive research exploring its impact [83]. In Europe, SCS implementation was much less controversial than in Canada, which generally resulted in smaller investment in evaluations of European SCS [40]. For example, although documentation and evaluation are legally required to operate an SCS in Germany, many of the early reports were to funders and focused on quality improvement rather than peer-reviewed evaluation of the sites [27]. This de-emphasis on research resulted in only $41 \%$ of the included articles being peer-reviewed, and over half of the articles being descriptive (i.e., did not systematically collect and analyze qualitative and/or quantitative data). While the provision of SCS should not be contingent on scientific evaluation, rigorous research on the range of extant models is essential to facilitate knowledge translation among other researchers and policy makers to ensure future implementation efforts are as effective as possible.

Adding to the lack of clarity in the literature, many terms to denote SCS were used in the included articles, often interchangeably, despite some of the terms having slightly different implications (e.g., different routes of consumption, different levels of service provision). The use of these many different terms also has implications for the level of support offered by the community [84]. Implementing a common nomenclature for reporting on SCS models and program participant characteristics should include a commitment to accurate terminology to describe these services, and may facilitate knowledge translation to members of the community, policy and decision makers, and other stakeholders.

We recommend standardizing conventions for describing SCS site and program participant characteristics to facilitate reporting and comparisons, and ensure the range of existing models is accurately represented. In particular, future survey research that aims to construct a census of existing service models, using standardized definitions to outline characteristics and describe program participant populations would greatly advance understanding of supervised non-injection drug consumption service models. It would also support those seeking to implement SCS in determining the site characteristics most appropriate for their specific context and potential trade-offs with choosing one type of model over another. Furthermore, a clear description of the site characteristics is necessary to systematically evaluate whether these
SCS are meeting their goals. The characteristics of people who use SCS depend in part on the target population, eligibility criteria, and layout of the SCS, and providing an aggregate summary of typical program participants of SCS may not be a useful measure despite the common aim to reduce harm to marginalized populations who are consuming drugs [3]. Instead, it may be more important to assess how well the site characteristics of each SCS are contributing to that site's overall objectives. In particular, future research should examine the impacts of SCS policies, and explore whether these policies inadvertently exacerbate inequities between different subpopulations of people who use drugs.

\section{Limitations}

This scoping review is subject to limitations, the first of which was the exclusion of articles that were not published in English. Many SCS that permit non-injection routes of consumption exist in Europe, and only including articles in English may have resulted in the exclusion of some relevant literature [57]. However, of the 807 fulltext articles we screened from the peer-reviewed databases, only 29 (3.6\%) were excluded because they were not available in English. This is consistent with other systematic reviews of supervised injection services [4], and the preponderance of information on SCS from predominantly English-speaking countries were also observed in reviews that did not limit their inclusion criteria to English language studies [3]. In addition, the majority of our included articles discussed SCS in Europe, including those located in countries where English is not the primary language spoken. Second, the nature of our study (a review of previously published literature) meant we were not able to reconcile inconsistent reporting between articles, which limits the clarity of site and program participant characteristics reported here. This is especially important as much of the data provided by the included articles were unclear; many articles discussed SCS characteristics in aggregate, did not specify which characteristics apply to each SCS, and/or provided conflicting information. However, this lack of clarity highlights the lack of standardized reporting of SCS and the need for more consistency moving forward. Third, while we identified 48 SCS in 6 countries as allowing alternate routes of consumption, this may be an underestimation of the diversity and total number of SCS that permit non-injection routes of consumption globally. We only report on SCS which are documented or described in the peerreviewed and grey literature; not all sites are documented in the literature, sites may have evolved or changed since publication, and more sites have been implemented since we conducted the search for this scoping review, particularly in Canada [81]. Finally, while no formal 
quality assessment is required for scoping reviews [85], not assessing the quality of the data provided by the articles may have placed inadvertent emphasis on lower quality data. Despite these limitations, our review is the first to comprehensively capture the existing data on SCS that permit non-injection routes of consumption and to recommend improvements to the current knowledge base.

\section{Conclusion}

Numerous articles discussed SCS that permit non-injection routes of consumption. Overall, the level of detail available regarding these sites is quite low, with inconsistent and imprecise reporting of the routes of consumption permitted, the site characteristics, and the characteristics of program participants of each site. While the evidence documenting the provision of supervised injection services is robust, there is comparatively limited literature discussing sites that allow alternate routes of consumption. Clear knowledge of existing SCS models that permit non-injection routes of consumption will facilitate further innovation, implementation, and evaluation of these services across jurisdictions.

\section{Supplementary information}

Supplementary information accompanies this paper at https://doi. org/10.1186/s12954-020-00414-y.

Additional file 1. All search strategies for databases not presented in the body of the manuscript.

Additional file 2. A list of all terms used in the grey literature search strategy.

Additional file 3. List of exemplar articles used to verify and test the search strategy.

Additional file 4. Full details of the screening process including grey literature screening, external reference list screening, and screening for reference list of included articles.

Additional file 5. Data extraction of SCS characteristics.

Additional file 6. Data extraction of program participant characteristics.

\section{Abbreviations}

CAD: Canadian dollar; HIV: Human immunodeficiency virus; NLG: Dutch guilder; PRISMA-SCR: PRISMA extension for scoping reviews; SCS: Supervised consumption services; USD: American dollar.

\section{Acknowledgements}

The authors thank Marilou Gagnon for expert advice on our search protocol, Arlanna Pugh and Hannah Brooks for their help in screening articles, and Cassandra Husband for assisting with data cleaning.

\section{Author's contributions}

EH was principal investigator of this study. EH and KS conceptualized the study protocol. SC and KS drafted and executed the search strategy. KS, NG, KL, and DOB screened titles and abstracts. KS, NG, KL, and DOB extracted the data. KS and NG analyzed the data. KS wrote the first draft of the manuscript. All authors provided comments and revisions on manuscripts drafts. All authors read and approved the final manuscript.

\section{Funding}

This research was funded in part by the Government of Alberta Ministry of Health via a grant to Access to Medically Supervised Injection Services in Edmonton. EH's faculty receives salary support from the Royal Alexandra Hospital Foundation and Alberta Health Services in support of her position. The research was conducted independently of the funders and conclusions herein do not necessarily represent their views.

\section{Availability of data and materials}

All data generated or analysed during this study are included in this published article and its supplementary files. Additional information may be provided upon reasonable request to the corresponding author.

\section{Ethics approval and consent to participate}

This study did not require ethical approval.

\section{Consent for publication}

This study does not contain any individual person's data in any form.

\section{Competing interests}

The authors declare that they have no competing interests.

\section{Author details}

${ }^{1}$ School of Public Health, University of Alberta, Edmonton, AB, Canada. ${ }^{2}$ Inner City Health and Wellness Program, Royal Alexandra Hospital, Edmonton, AB, Canada. ${ }^{3}$ John W. Scott Health Sciences Library, University of Alberta, Edmonton, $\mathrm{AB}$, Canada.

Received: 15 June 2020 Accepted: 16 September 2020 Published online: 07 October 2020

\section{References}

1. Schatz E, Nougier M. IDPC briefing paper: drug consumption rooms evidence and pratice. International Drug Policy Consortium. 2012.

2. Harm Reduction International. Drug consumption rooms: global state of harm reduction 2018 briefing.

3. Kennedy MC, Karamouzian M, Kerr T. Public health and public order outcomes associated with supervised drug consumption facilities: a systematic review. Curr HIV/AIDS Rep. 2017;14(5):161-83.

4. Potier C, Laprévote V, Dubois-Arber F, Cottencin O, Rolland B. Supervised injection services: what has been demonstrated? A systematic literature review. Drug Alcohol Depend. 2014;145:48-68.

5. United Nations. World drug report 2019. 2019. https://wdr.unodc.org/ wdr2019/prelaunch/WDR19_Booklet_2_DRUG_DEMAND.pdf. Accessed 20 Jan 2020.

6. Onyeka IN, Basnet S, Beynon CM, Tiihonen J, Föhr J, Kauhanen J. Association between routes of drug administration and all-cause mortality among drug users. J Subst Use. 2016;21(6):559-65.

7. Alberta Health, Government of Alberta, Alberta Health. Opioid-related deaths in Alberta in 2017: review of medical examiner data. 2019. https:// open.alberta.ca/dataset/f9912915-bd4f-4b57-93bf-2a963cb99038/resou rce/a2857fb6-6663-491c-b9df-686e348bb456/download/070519-mechart-review-final.pdf. Cited 2020 Jan 16.

8. Darke S, Ross J. Fatal heroin overdoses resulting from non-injecting routes of administration, NSW, Australia, 1992-1996. Addiction. 2000;95(4):569-73.

9. Baldwin N, Gray R, Goel A, Wood E, Buxton JA, Rieb LM. Fentanyl and heroin contained in seized illicit drugs and overdose-related deaths in British Columbia, Canada: an observational analysis. Drug Alcohol Depend. 2018;185:322-7.

10. Klar S, Brodkin E, Gibson E, Padhi S, Predy C, Green C, et al. Furanyl-fentanyl overdose events caused by smoking contaminated crack cocaineBritish Columbia, Canada, July 15-18, 2016. Health Promot Chronic Dis Prev Can. 2016:36(9):200-1.

11. McLean K, Monnat SM, Rigg K, Sterner GE, Verdery A. "You never know what you're getting": opioid users' perceptions of fentanyl in southwest Pennsylvania. Subst Use Misuse. 2019;54(6):955-66. 
12. Fischer B, Powis J, Cruz MF, Rudzinski K, Rehm J. Hepatitis C virus transmission among oral crack users: viral detection on crack paraphernalia. Eur J Gastroenterol Hepatol. 2008;20(1):29-32.

13. Tortu S, McMahon JM, Pouget ER, Hamid R. Sharing of noninjection drug-use implements as a risk factor for hepatitis C. Subst Use Misuse. 2004;39(2):211-24.

14. DeBeck K, Kerr T, Li K, Fischer B, Buxton J, Montaner J, et al. Smoking of crack cocaine as a risk factor for HIV infection among people who use injection drugs. Can Med Assoc J. 2009;181(9):585-9.

15. Jozaghi E, Lampkin $H$, Andresen MA. Peer-engagement and its role in reducing the risky behavior among crack and methamphetamine smokers of the downtown eastside community of Vancouver, Canada. Harm Reduct J. 2016;13(19):1-9.

16. McNeil R, Kerr T, Lampkin H, Small W. "We need somewhere to smoke crack": an ethnographic study of an unsanctioned safer smoking room in Vancouver, Canada. Int J Drug Policy. 2015;26:645-52.

17. Bourque S, Pijl EM, Mason E, Manning J, Motz T. Supervised inhalation is an important part of supervised consumption services. Can J Public Health. 2019;110(2):210-5.

18. Ivsins A, Roth E, Nakamura N, Krajden M, Fischer B. Uptake, benefits of and barriers to safer crack use kit (SCUK) distribution programmes in Victoria, Canada—a qualitative exploration. Int J Drug Policy. 2011;22(4):292-300.

19. Prangnell A, Dong H, Daly P, Milloy MJ, Kerr T, Hayashi K. Declining rates of health problems associated with crack smoking during the expansion of crack pipe distribution in Vancouver, Canada. BMC Public. 2017;17(1). https://doi.org/10.1186/s12889-017-4099-9.

20. Pauly B, Wallace B, Pagan F, Phillips J, Wilson M, Hobbs H, et al. Impact of overdose prevention sites during a public health emergency in Victoria, Canada. Panagiotoglou D, editor. PLOS ONE. 2020;15(5):e0229208.

21. Collins CLC, Kerr T, Tyndall MW, Marsh DC, Kretz PS, Montaner JS, et al. Rationale to evaluate medically supervised safer smoking facilities for non-injection illicit drug users. Can J Public Health. 2005;96(5):344-7.

22. Kelley MS, Chitwood DD. Effects of drug treatment for heroin sniffers: a protective factor against moving to injection? Soc Sci Med. 2004:58(10):2083-92.

23. Elhalifa S, Jozaghi E, Marsh S, Thomson E, Gregg D, Buxton J, et al. Combining chain link sampling with a community-based participatory action study of people who smoke drugs in two cities in British Columbia, Canada. 2020. https://www.researchsquare.com/article/rs-21315/v1. Cited 2020 Jul 8.

24. Elkhalifa S, Jozaghi E, Marsh S, Thomson E, Gregg D, Buxton J, et al. Social network support and harm reduction activities in a peer led pilot study, British Columbia, Canada. 2020. https://www.researchsquare.com/article/ rs-20967/v2. Cited 2020 Jul 8.

25. Domier CP, Simon SL, Rawson RA, Huber A, Ling W. A comparison of injecting and noninjecting methamphetamine users. J Psychoact Drugs. 2000:32(2):229-32.

26. Scheinmann R, Hagan H, Lelutiu-Weinberger C, Stern R, Jarlais DCD, Flom $P L$, et al. Non-injection drug use and hepatitis $C$ virus: a systematic review. Drug Alcohol Depend. 2007;89(1):1-12.

27. Hedrich D. European report on drug consumption rooms. European Monitoring Centre for Drugs and Drug Addiction. 2004. https://www. emcdda.europa.eu/attachements.cfm/att_2944_EN_consumptio n_rooms_report.pdf. Accessed 12 Oct 2018.

28. Arksey H, O'Malley L. Scoping studies: towards a methodological framework. Int J Soc Res Methodol. 2005;8(1):19-32.

29. Tricco AC, Lillie E, Zarin W, O'Brien KK, Colquhoun H, Levac D, et al. PRISMA extension for scoping reviews (PRISMA-SCR): checklist and explanation. Ann Intern Med. 2018;169(7):467.

30. Popay J, Roberts H, Sowden A, Petticrew M, Arai L, Rodgers M, et al. Guidance on the conduct of narrative synthesis in systematic reviews: a product from the ESRC Methods Programme. Lancaster: Lancaster University; 2006. https://doi.org/10.13140/2.1.1018.4643.

31. Kerr T, Baltzer Turje R, Buchner C, Davis M, Johnson C, Lem M, et al. Supervised consumption services: operational guidance. British Columbia Centre on Substance Use, British Columbia Ministry of Health; n.d. https ://towardtheheart.com/assets/uploads/1504645603PziOGGINIhYQ7LM crhsGZC7wRMWDbliYZsrHX2G.pdf. Accessed 13 Oct 2018.

32. van der Poel A, Barendregt C, van de Mheen D. Drug consumption rooms in Rotterdam: an explorative description. Eur Addict Res. 2003:9(2):94-100.
33. ZEUS GmbH. Evaluation of the work of drug consumption rooms in the Federal Republic of Germany. Bochum: ZEUS GmbH Centre for Applied Psychology, Environmental and Social Research; 2003. https://www.tni. org/en/publication/evaluation-of-the-work-of-drug-consumption-rooms -in-the-federal-republic-of-germany. Accessed 14 Oct 2018.

34. Joint Select Committee into Safe Injecting Rooms. Report on the establishment or trial of safe injecting rooms. Sydney: Parliament of New South Wales; 1998. https://www.parliament.nsw.gov.au/lcdocs/inquiries/2042/ Committee\%20Report\%2018\%20February\%201998\%20-\%20Inquiry\%20 into\%20S.pdf. Accessed 13 Oct 2018.

35. Kerr T. Safe injection facilities: Proposal for a Vancouver pilot project. Harm Reduction Action Society; 2000. https://fileserver.idpc.net/libra ry/Safe\%2OInjection\%20Facilities\%20-\%20Proposal\%20for\%20a\%20Van couver\%20Pilot\%20Project.pdf.

36. Toth EC, Tegner J, Lauridsen S, Kappel N. A cross-sectional national survey assessing self-reported drug intake behavior, contact with the primary sector and drug treatment among service users of Danish drug consumption rooms. Harm Reduct J. 2016;13(1):27.

37. Gerlach R, Schneider W. Consumption and injecting room (CIR) at INDRO, Munster, Germany: Annual report 2002 (English version) - report period: January to December 2002. Munster, Germany: INDRO e.V;; 2003. https:// indro-online.de/en/consumption-and-injecting-room-cir/. Accessed 12 Oct 2018.

38. Stoever $\mathrm{H}$. Consumption rooms - a middle ground between health and public order concerns. J Drug Issues. 2002;32(2):597-606.

39. Fischer B, Allard C. Feasibility study on "supervised drug consumption" options in the city of Victoria. Victoria: Centre for Addictions Research of British Columbia, University of Victoria; 2007. https://www.uvic.ca/resea rch/centres/cisur/assets/docs/report-feasibility-supervised-drug-consu mption.pdf.

40. Hunt N. Paper B: the evaluation literature on drug consumption rooms. York: Joseph Rowntree Foundation; 2006a. https://www.jrf.org.uk/sites/ default/files/jrf/migrated/files/Hunt-DCR-B.pdf.

41. Jozaghi E, Vancouver Area Network of Drug Users. A cost-benefit/ cost-effectiveness analysis of an unsanctioned supervised smoking facility in the downtown eastside of Vancouver, Canada. Harm Reduct J. 2014;11(1):1-8.

42. Zurhold H, Degkwitz P, Verthein U, Haasen C. Drug consumption rooms in Hamburg, Germany: evaluation of the effects on harm reduction and the reduction of public nuisance. J Drug Issues. 2003;33(3):663-88.

43. AK Konsumraum. Drug consumption rooms in Germany: a situational assessment by the AK Konsumraum. Berlin, Germany: Deutsche AIDSHilfe e.V., akzept e.V. Federal Association for Accepting Drug Work and Humane Drug Policy; 2011. https://www.akzept.org/pdf/aktuel_pdf/ DKR07af1Eng.pdf. Accessed 12 Oct 2018.

44. Schäffer D, Stöver H, Weichert L. Drug consumption rooms in Europe: models, best practice and challenges. Amsterdam: European Harm Reduction Network; 2014. https://www.aidshilfe.de/sites/default/files/ documents/Drug\%20consumption\%20in\%20Europe.pdf.

45. Stöver HJ, Schäffer D. SMOKE IT! Promoting a change of opiate consumption pattern—from injecting to inhaling. Harm Reduct J. 2014;1 1(1):18.

46. Origer A, Lopes da Costa S, Diederich C, Schram S. 2016 National drug report: the state of the drugs problem in the Grand Duchy of Luxembourg. Luxembourg: Luxembourg Institute of Health; 2016. https://sante .public.lu/fr/publications/e/etat-drogue-gdl-rapport-relis-2016-fr-en/ index.html. Accessed 14 Oct 2018.

47. Otter D. Safe consumption facilities: evidence and models. n.d. https ://www.kingcounty.gov/ /media/depts/community-human-services/ behavioral-health-recovery/documents/herointf/Safe_Consumptio n_Facilities_Evidence_Models.ashx?la=en. Accessed 14 Oct 2018.

48. Peacey J. Drug consumption rooms in Europe: client experience survey in Amsterdam and Rotterdam. Amsterdam: European Harm Reduction Network; 2014. https://www.academia.edu/9215441/Drug_Consumptio n_Rooms_in_Europe_Client_experience_survey_in_Amsterdam_and_ Rotterdam. Accessed 14 Oct 2018.

49. San Francisco Department of Public Health, Aragon TJ. Harm reduction services in San Francisco. San Francisco: San Francisco Department of Public Health; 2017. https://www.sfdph.org/dph/files/SIStaskforce/lssue Brief-06202017.pdf.

50. Stöver H, Förster S, Padberg C. Monitoring report of the 4 drug consumption rooms (DCRs) in Frankfurt/Germany (1 Jan-31 Dec 2014). Frankfurt: 
Institution of Addiction Research, Frankfurt University of Applied Sciences; n.d. https://www.researchgate.net/publication/301659525_Monit oring_Report_of_the_4_Drug_Consumption_Rooms_DCRs_in_Frank furtGermany_1_Jan_-_31_Dec_2014. Accessed 14 Oct 2018.

51. Weekes J, Percy L, Cumberland K. Supervised injection facilities (SIFs) FAQs. Ottawa: Canadian Centre on Substance Abuse; 2005. https://www. ccsa.ca/sites/default/files/2019-04/ccsa-010657-2004.pdf.

52. Zobel F, Dubois-Arber F. Short appraisal of the role and usefulness of drug consumption facilities (DCF) in the reduction of drug-related problems in Switzerland: appraisal produced at the request of the Swiss Federal Office of Public Health. Lausanne: University Institute of Social and Preventative Medicine; 2004. https://serval.unil.ch/notice/serval:BIB_7945574468C3.

53. Home Office. Drugs: international comparators. UK: GOV.UK; 2014.

54. Hunt N. Paper C: an overview of models of delivery of drug consumption rooms. York: Joseph Rowntree Foundation; 2006b. http://neilhunt.org/ Reports/2006-JRF-drug-consumption-rooms-models-of-delivery-hunt. pdf.

55. Wolf J, Linssen L, de Graaf I. Drug consumption facilities in the Netherlands. J Drug Issues. 2003;33(3):649-61.

56. Drugs and Crime Prevention Committee. Inquiry into the inhalation of volatile substances: discussion paper. Melbourne: Parliament of Victoria; 2002. https://www.parliament.vic.gov.au/images/stories/committees/ dcpc/Volatile_substances/Volatile_Substances_discuss_paper1.pdf.

57. Belackova V, Salmon AM, Day CA, Ritter A, Shanahan M, Hedrich D, et al. Drug consumption rooms: a systematic review of evaluation methodologies. Drug Alcohol Rev. 2019;38(4):406-22.

58. van Beek I. The Sydney medically supervised injecting centre: a clinical model. J Drug Issues. 2003;33(3):625-38.

59. Ponton R, Scott J. Injection preparation processes used by heroin and crack cocaine injectors. J Subst Use. 2004;9(1):7-19.

60. Tupper KW, McCrae K, Garber I, Lysyshyn M, Wood E. Initial results of a drug checking pilot program to detect fentanyl adulteration in a Canadian setting. Drug Alcohol Depend. 2018;190:242-5.

61. Karamouzian M, Dohoo C, Forsting S, McNeil R, Kerr T, Lysyshyn M. Evaluation of a fentanyl drug checking service for clients of a supervised injection facility, Vancouver, Canada. Harm Reduct J. 2018;15(1):46.

62. Olding M, Ivsins A, Mayer S, Betsos A, Boyd J, Sutherland C, et al. A lowbarrier and comprehensive community-based harm-reduction site in Vancouver, Canada. Am J Public Health. 2020;1 10(6):833-5.

63. Ivsins A, Boyd J, Beletsky L, McNeil R. Tackling the overdose crisis: the role of safe supply. Int J Drug Policy. 2020;80:102769.

64. Fleming T, Barker A, Ivsins A, Vakharia S, McNeil R. Stimulant safe supply: a potential opportunity to respond to the overdose epidemic. Harm Reduct J. 2020. https://doi.org/10.1186/s12954-019-0351-1.

65. Kerr T. Public health responses to the opioid crisis in North America. J Epidemiol Community Health. 2019;73(5):377-8.

66. Jozaghi E, Maynard R, Hamm D, Marsh S. COVID-19 and people who use drugs: a call for action. Can J Public Health. 2020;111(3):401-2.

67. Harris M. An urgent impetus for action: safe inhalation interventions to reduce COVID-19 transmission and fatality risk among people who smoke crack cocaine in the United Kingdom. Int J Drug Policy. 2020. https ://www.ncbi.nlm.nih.gov/pmc/articles/PMC7306748/. Cited 2020 Jul 31.

68. Pagliaro J. City's busiest supervised injection site to reopen after monthlong closure over COVID-19. The Star. 2020. https://www.thestar.com/ news/city_hall/2020/04/16/citys-busiest-supervised-injection-site-toreopen-after-month-long-closure-over-covid-19.html. Accessed 10 July 2020.

69. de Villa E. Update on COVID-19. Toronto Public Health; 2020. https://www. toronto.ca/wp-content/uploads/2020/04/9763-MOH-Statement_16Apr il2020.pdf. Accessed 10 July 2020.

70. Allan M. Due to COVID-19, low attendance at supervised drug consumption site in Calgary may increase risk of overdoses. The Globe and Mail. 2020. https://www.theglobeandmail.com/canada/alberta/article-plumm eting-attendance-at-supervised-drug-consumption-site-in-calgary/.

71. El-Bassel N, Strathdee SA. Women who use or inject drugs: an action agenda for women-specific, multilevel, and combination HIV prevention and research. J Acquir Immune Defic Syndr. 2015;69:S182-90.

72. Fennema JS, Van Ameijden EJ, Van Den Hoek A, Coutinho RA. Young and recent-onset injecting drug users are at higher risk for HIV. Addict Abingdon Engl. 1997;92(11):1457-65.
73. Miller CL, Strathdee SA, Kerr T, Li K, Wood E. Factors associated with early adolescent initiation into injection drug use: implications for intervention programs. J Adolesc Health. 2006;38(4):462-4.

74. Merkinaite S, Grund JP, Frimpong A. Young people and drugs: next generation of harm reduction. Int J Drug Policy. 2010;21(2):112-4.

75. Watson TM, Strike C, Kolla G, Penn R, Bayoumi AM. “Drugs don't have age limits": the challenge of setting age restrictions for supervised injection facilities. Drugs Educ Prev Policy. 2015;22(4):370-9.

76. Montero-Moraga JM, Garrido-Albaina A, Barbaglia MG, Gotsens M, Aranega D, Espelt A, et al. Impact of 24-hour schedule of a drug consumption room on service use and number of non-fatal overdoses. A quasiexperimental study in Barcelona. Int J Drug Policy. 2020;81:102772.

77. McNeil R, Dilley LB, Guirguis-Younger M, Hwang SW, Small W. Impact of supervised drug consumption services on access to and engagement with care at a palliative and supportive care facility for people living with HIV/AIDS: a qualitative study. J Int AIDS Soc. 2014;17(1):18855.

78. Kappel N, Toth E, Tegner J, Lauridsen S. A qualitative study of how Danish drug consumption rooms influence health and well-being among people who use drugs. Harm Reduct J. 2016;13(1):20.

79. Kerr T, Oleson M, Tyndall MW, Montaner J, Wood E. A description of a peer-run supervised injection site for injection drug users. J Urban Health. 2005;82(2):267-75.

80. Russell C, Imtiaz S, Ali F, Elton-Marshall T, Rehm J.'Small communities, large oversight': the impact of recent legislative changes concerning supervised consumption services on small communities in Ontario, Canada. Int J Drug Policy. 2020;82:102822.

81. Government of Canada. Supervised consumption sites: status of applications. 2017. https://www.canada.ca/en/health-canada/services/subst ance-use/supervised-consumption-sites/status-application.html. Cited 2020 Feb 3.

82. Government of Canada. Supervised consumption sites explained. 2018. https://www.canada.ca/en/health-canada/services/substance-use/super vised-consumption-sites/explained.html. Cited 2020 Feb 3.

83. Hyshka E, Bubela T, Wild TC. Prospects for scaling-up supervised injection facilities in Canada: the role of evidence in legal and political decisionmaking. Addiction. 2013;108(3):468-76.

84. Barry CL, Sherman SG, McGinty EE. Language matters in combatting the opioid epidemic: safe consumption sites versus overdose prevention sites. Am J Public Health. 2018;108(9):1157-9.

85. Grant MJ, Booth A. A typology of reviews: an analysis of 14 review types and associated methodologies. Health Inf Libr J. 2009;26(2):91-108.

86. Campbell L. Chemical intent: Imagining the drug using client and the human service worker in harm minimisation policy. Doctoral dissertation, Australian Catholic University, Fitzroy; 2007. https://researchbank.acu. edu.au/cgi/viewcontent.cgi?referer=https://www.google.ca/\&httpsredir $=1 \&$ article $=1192 \&$ context $=$ theses. Accessed 15 Oct 2018.

87. Kerr T, Mitra S, Kennedy MC, McNeil R. Supervised injection facilities in Canada: past, present, and future. Harm Reduct J. 2017;14(1):1-9.

88. Gardner A. Supervised injection facilities and social services: An evaluation of social service provision and treatment uptake from managerial perspectives. Masters thesis, Icahn School of Medicine at Mount Sinai, New York; 2017. https://search.proquest.com/docview/1875556410?pqorigsite=gscholar. Accessed 15 Oct 2018.

89. Scherbaum N, Specka M, Schifano F, Bombeck J, Marrziniak B. Longitudinal observation of a sample of German drug consumption facility clients. Subst Use Misuse. 2010;45(1-2):176-89.

90. International Network of Drug Consumption Rooms. Luxembourg overview. International Network of Drug Consumption Rooms. 2015. https://www.drugconsumptionroom-international.org/index.php/locat ions/2015-09-27-13-37-46/location-luxembourg. Cited 2018 Apr 26.

91. Temenos C. Everyday proper politics: rereading the post-political through mobilities of drug policy activism. Trans Inst Br Geogr. 2017:42(4):584-96.

\section{Publisher's Note}

Springer Nature remains neutral with regard to jurisdictional claims in published maps and institutional affiliations. 